\title{
Guy de Maupassant, Théâtre
}

\section{Ida Merello}

\section{(2) OpenEdition}

\section{Journals}

\section{Edizione digitale}

URL: http://journals.openedition.org/studifrancesi/3817

DOI: 10.4000/studifrancesi.3817

ISSN: 2427-5856

\section{Editore}

Rosenberg \& Sellier

\section{Edizione cartacea}

Data di pubblicazione: 1 décembre 2012

Paginazione: 597-598

ISSN: 0039-2944

\section{Notizia bibliografica digitale}

Ida Merello, «Guy de Maupassant, Théâtre», Studi Francesi [Online], 168 (LVI | III) | 2012, online dal 30 novembre 2015, consultato il 05 mars 2021. URL: http://journals.openedition.org/studifrancesi/3817 ; DOI: https://doi.org/10.4000/studifrancesi.3817

Questo documento è stato generato automaticamente il 5 mars 2021.

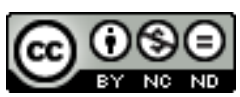

Studi Francesi è distribuita con Licenza Creative Commons Attribuzione - Non commerciale - Non opere derivate 4.0 Internazionale. 


\title{
Guy de Maupassant, Théâtre
}

\author{
Ida Merello
}

\section{NOTIZIA}

GUY DE MAUPASSANT, Théâtre. Texte présenté, établi et annoté par Noëlle BENHAMOU, Paris, Ed. du Sandre, 2012, pp. 512.

1 Il volume riunisce per la prima volta le pièces messe in scena quando l'autore era vivente, in ordine di pubblicazione: tuttavia À la feuille de rose, maison turque, che è stata pubblicata solo nel 1945, ma è stata recitata dal 1875, è posta all'inizio del volume; mentre l'A. ha deliberatamente espunto Mme Thomassin, reclamando la mancanza di un manoscritto autografo di Maupassant, e suggerendo che lo scrittore abbia solo fornito lo spunto a William Busnach, l'unico ad aver firmato la pièce. In totale perciò troviamo À la feuille de rose, maison turque (1875), Histoire du vieux temps (1879), Une répétition (1880), Musotte (1891), La Paix du ménage (1893). In appendice sono inseriti invece La Trahison de la Comtesse de Rhune (1877), che costituisce un prima versione di La Comtesse de Rhétune, conservata presso la biblioteca municipale di Rouen, il sainete La Revanche (1886) e tre racconti da cui sono state ricavate delle pièces teatrali: L'Enfant (1882), Au bord du lit (1883) e Étrennes (1887). Viene offerto alla lettura anche il pastiche di Albert Guinon, che riprende i due racconti Un fils (1882) e L'Abandonné (1884) per aggiungere due scene e modificare la conclusione di Musotte - dal momento che l'adozione da parte della moglie del figlio naturale del marito non sembrava accettabile. La curatrice ha compiuto un'operazione improrogabile, visto che a tutt'oggi non esisteva un'edizione commentata, e quella di Jean Bonnot del 1980 si limitava a riproporre i testi già organizzati da Pascal Pia. Per le pièces pubblicate, N. Benhamou si è rifatta alla prima edizione in plaquette, confrontata con le successive e normalizzata dal punto di vista ortografico (eliminazione degli errori tipografici, omogeneizzazione della grafia con la scelta di quella più moderna, tranne che nelle pièces in versi, per ovvie necessità metriche e ritmiche). 
2 La presentazione dell'opera è pretesto per una contestualizzazione del teatro di Maupassant rispetto al teatro borghese di fine secolo, che portava una nuova attenzione nei confronti del matrimonio e delle rivendicazioni femminili. La curatrice mette in luce la solidarietà di Maupassant con le mal mariées, e ne sottolinea la ben nota capacità di interpretare finemente la sensibilità femminile e i risvolti più complessi della sessualità. Ogni pièce è quindi preceduta da un'ampia presentazione e accompagnata da una ricca bibliografia, che tiene conto non solo delle rappresentazioni, ma anche degli adattamenti cinematografici e per disegni animati. Nella postfazione la curatrice esamina con particolare attenzione la passione di Maupassant per il teatro, la volontà di sperimentarne tutti i generi, l'interesse per le Comédies-proverbes di Musset, la presa di distanza rispetto l'estetica del Naturalisme au théâtre di Zola. È messa in evidenza la contraddizione tra una critica sostanziale del meccanismo teatrale e un'invincibile attrazione anche nei confronti dei suoi aspetti più funzionali. Viene infine ricordato come Maupassant rifiuti, al contrario di molti romanzieri naturalisti, rapporti di collaborazione per ricavare pièces dalle sue novelle, scegliendo piuttosto di riscriverle sotto forma drammatica. Noëlle Benhamou mostra così come dal conte alla pièce si possa cogliere un'evoluzione della riflessione dello scrittore, e sottolinea l'ambizione di emergere nel genere teatrale, non solo per orgoglio, ma anche per autentica passione. 